\title{
Potencial de aplicação do biossurfactante por serratia mascescens UCP 1549 na descontaminação ambiental
}

\section{Potential for the application of the biosurfactor by serratia mascescens UCP 1549 in environmental decontamination}

\author{
Data de entrada: \\ 08/10/2018 \\ Data de aprovação: \\ $04 / 12 / 2019$
}

Helvia Waleska Casullo de Araújo' | Galba Maria Campos Takaki | Rosileide Fontenele da Silva Andrade ${ }^{3}$ | Dayana Montero Rodríguez ${ }^{4}$ | Laís Montenegro Teixeira ${ }^{1 *}$
DOI: https://doi.org/10.36659/dae.2021.011
ORCID ID

Araújo HWC (D) https://orcid.org/0000-0003-0337-5986

Takaki GMC (D) https://orcid.org/0000-0002-0519-0849

\begin{abstract}
Andrade RFS (D) https://orcid.org/0000-0001-8526-554X Rodríguez DM (D) https://orcid.org/0000-0001-8954-7309 Teixeira LM (D) https://orcid.org/0000-0001-8146-5982
\end{abstract}

\section{Resumo}

Este trabalho avalia a influência das cascas de abacaxi e da gordura animal como substratos para a produção de biossurfactantes por Serratia marcescens UCP 1549, de acordo com o planejamento fatorial 22. As variáveis medidas foram emulsificação e tensão superficial utilizando os substratos hidrofóbicos óleo pós-fritura, óleo de milho e óleo de girassol. O melhor resultado obtido para índice de emulsificação e tensão superficial, respectivamente, foi de $100 \%$ na condição fermentada por $96 \mathrm{~h}$ e $27,7 \mathrm{mN} / \mathrm{m}$ na condição fermentada por $48 \mathrm{~h}$. Com a melhor condição representada pelo resultado da redução da tensão superficial foi produzido $1 \mathrm{~L}$ do meio para a sua extração. Os resultados demonstram boa capacidade de S. marcescens UCP 1549 para produzir biossurfactante com propriedades para aplicações na descontaminação ambiental de petróleo e derivados. Palavras-chave: Índice de emulsificação. Tensão superficial. Extração.

\section{Abstract}

The present work evaluates the influence of pineapple pees and animal fat as substrates for biosurfactants production by Serratia marcescens UCP 1549, in a 22 factorial design. The measured variables were emulsification and surface tension using the hydrophobic substrates post-frying oil, corn oil and sunflower oil. The best result obtained for emulsification index and surface tension, respectively, was 100\% in the fermented condition for $96 \mathrm{~h}$ and 27.7 $\mathrm{mN} / \mathrm{m}$ in the fermented condition for $48 \mathrm{~h}$. With the best condition represented by the result of the reduction of the surface tension, $1 \mathrm{~L}$ of the medium was produced for its extraction. The results demonstrate good ability of S. marcescens UCP 1549 to produce biosurfactant with properties to apply to environmental decontamination of petroleum and derivatives.

Keywords: Emulsification index. Surface tension. Extraction.

\footnotetext{
${ }^{1}$ Universidade Estadual da Paraíba - Campina Grande - Paraíba - Brasil.

${ }^{2}$ Universidade Federal de São Paulo - São Paulo - São Paulo - Brasil.

${ }^{3}$ Universidade Federal de Pernambuco - Recife - Pernambuco - Brasil.

${ }^{4}$ Universidade Católica de Petrópolis - Petrópolis - Rio de Janeiro - Brasil.

* Autora correspondente: laismontenegrotagmail.com.
} 


\section{INTRODUÇÃO}

Os constantes acidentes ambientais envolvendo derramamentos de petróleo e seus derivados vêm desencadeando a preocupação com o desenvolvimento de técnicas que objetivam a descontaminação das regiões impactadas (LAWNICZAK, MARECIK, CHRZANOWSK, 2013). Os hidrocarbonetos são descritos como potenciais extremamente poluentes, tóxicos, cancerígenos e mutagênicos para humanos, além de apresentarem uma complexa remoção do meio ambiente, pois eles se ligam a diferentes matrizes devido à sua propriedade hidrofóbica. A contaminação da água e do solo por hidrocarbonetos aromáticos vem aumentando devido à sua utilização em vários segmentos industriais e os métodos de remediação para esses ambientes contaminados são baseados em atividades química, física ou biológica, a exemplo da utilização de surfactes químicos que estão disponíveis comercialmente, sendo estes derivados do petróleo. (MORAIS et al., 2015).

Atualmente, os surfactantes são comercializados quase exclusivamente sintéticos e são sintetizados por matérias-primas não renováveis, principalmente os derivados do petróleo. Alguns exemplos de surfactantes usados comercialmente incluem ésteres sulfatados ou sulfatos de ácidos graxos (aniônicos) e sais de amônio quaternário (catiônioco) (NITSCHKE e PASTORE, 2002).

A presença de surfactantes nos corpos hídricos acarreta a formação de uma espuma na superfície da água, diminuindo, assim, a penetração dos raios solares, reduzindo a solubilidade do oxigênio devido a compostos químicos presentes em sua composição, os quais na maioria liberam toxinas cancerígenas no meio ambiente (REDDY et al., 2012). Um exemplo da formulação de alguns surfactantes produzidos são sais contendo o grupo fosfato, como o tripolifosfato de sódio. O fosfato, presente no efluente devido ao uso desses detergentes, é utilizado como nutriente pela vegetação aquática superficial, favorecendo a eutrofização no meio (OLKOWSKA, RUMAN, POLKOWSKA, 2014).

Considerando a crescente preocupação ambiental e econômica, a substituição dos surfactantes químicos pelos biológicos torna-se de grande interesse devido às características de baixa toxidade, biodegradabilidade e síntese a partir de fontes renováveis e de baixo custo, fatores esses que os caracterizam como compostos reconhecidamente seguros e que apresentam, então, menor impacto ambiental (CAMPOS-TAKAKI, SARUBBO, ALBUQUUERQQUE, 2010).

Os biossurfactantes, semelhantes aos surfactantes sintéticos, apresentam em sua molécula uma porção hidrofóbica e uma porção hidrofílica. São surfactantes produzidos principalmente por microrganismos que possuem a função biológica de obter o acesso a substratos hidrofóbicos, aumentando sua disponibilidade de nutrientes para os microrganismos produtores, e exposição a bactérias, favorecendo a biodegradação de hidrocarbonetos. Uma das características mais importantes do biossurfactante produzido é a sua capacidade para emulsionar hidrocarbonetos em solução, produzindo agentes tensoativos que podem causar a dispersão de hidrocarbonetos em emulsões de água em micro gotas ou micelas (a concentração mínima na qual se inicia a formação de micelas chama-se concentração micelar crítica), ou seja, possuem atividade superficial, reduzindo assim a tensão superficial e interfacial entre gases, líquidos e sólidos e, consequentemente, permitindo que essas fases se misturem e interajam mais facilmente (IBRAHIM et al., 2013).

Os biossurfactantes são estáveis, mesmo em condições extremas, em uma ampla gama de $\mathrm{pH}$, temperatura e salinidade, e sua produção é afetada por vários fatores que dependem do microrganismo utilizado, meio (fonte de Carbono, Ni- 
trogênio e salinidade) e condições operacionais ( $\mathrm{pH}$, temperatura e velocidade de agitação).

Serratia marcescens tem sido relatada como um microrganismo promissor na biodegradação de petróleo e derivados em processos de descontaminação ambiental (OKORO et al., 2012; IBRAHIM et al., 2013). A ampliação da escala de produção de biossurfactante por Serratia marcescens, nas condições otimizadas, representa considerável contribuição à saúde pública e ao meio ambiente, tendo em vista a persistência e a toxicidade dos hidrocarbonetos aromáticos policíclicos derivados do petróleo, em especial o óleo diesel.

O grande problema na produção dos biossurfactantes é o custo envolvido no processo. As principais razões para esse fato estão relacionadas à baixa produtividade das linhagens e à necessidade de uso de substratos caros, sendo a fonte de carbono, como os alcanos, responsável por parte considerável desses custos. As fontes mais exploradas para a extração dos biossurfactantes são matérias-primas renováveis, proteínas e sais minerais industrializados (LI et al., 2016).

Como consequência, são realizadas diversas pesquisas avaliando subprodutos e rejeitos agroindustriais como fontes nutricionais alternativas, tornando-se uma estratégia atraente e de baixo custo e possibilitando a minimização dos problemas ambientais causados pelo descarte sem o tratamento prévio e tornando estes bioprodutos economicamente competitivos (BERGER et al., 2014). O uso de resíduos agroindustriais como meio de cultura é uma alternativa para reduzir os custos de produção para ampliação das possibilidades de aplicação, uma vez que a matériaprima representa $30 \%$ de custos totais em um processo biotecnológico (BARROS et al., 2007).

Os resíduos de várias frutas, legumes e hortaliças são, na maioria das vezes, desprezados pelas indústrias. Atualmente, esses resíduos estão sendo utilizados como fonte alternativa de nutrien- tes para a produção de biopolímeros. $\mathrm{O}$ abacaxi destaca-se por seu valor energético, devido à sua alta composição de açúcares e valor nutritivo pela presença de sais minerais e vitaminas. A gordura animal e o sebo podem ser obtidos em grandes quantidades nas indústrias de processamento de carne. Essas gorduras têm perdido a maior parte do mercado para os óleos vegetais devido ao menor dano provocado por estes últimos à saúde (MANEERAT, 2005).

Será explorado neste trabalho o potencial dos resíduos sólidos, como cascas de abacaxi, e rejeitos de gordura animal, objetivando alcançar um correto balanço nutricional entre fonte de carbono e nitrogênio na produção de biossurfactante pela bactéria Serratia marcescens UCP 1549, utilizando como substrato gordura animal e óleos vegetais pós-fritura. Além disso, tal processo se torna uma estratégia atraente e de baixo custo para a produção desse metabólito secundário por promover a minimização dos problemas ambientais causados por esses rejeitos.

\section{OBJETIVO}

O presente trabalho teve como objetivo produzir um biossurfactante com potencial de aplicação na descontaminação ambiental de petróleo e derivados com baixo custo.

\section{METODOLOGIA}

\subsection{Planejamento fatorial Delineamento Composto Central (DCC)}

O experimento foi realizado com o planejamento experimental Delineamento Composto Central (DCC) do tipo 22, sendo realizado de acordo com as condições estabelecidas na Tabela 1 com o objetivo de avaliar a influência das variáveis independentes casca de abacaxi e gordura animal sobre a variável resposta tensão superficial e índice de emulsificação. 
Tabela 1 - Matriz codificada do planejamento fatorial DCC 22

\begin{tabular}{|c|c|c|}
\hline Condições & Casca de abacaxi & Gordura animal \\
\hline $\mathbf{1}$ & -1 & -1 \\
\hline $\mathbf{2}$ & 1 & 1 \\
\hline $\mathbf{3}$ & -1 & 1 \\
\hline $\mathbf{4}$ & 1 & -1 \\
\hline $\mathbf{5}$ & 0 & 0 \\
\hline $\mathbf{6}$ & 0 & 0 \\
\hline $\mathbf{7}$ & 0 & 0 \\
\hline $\mathbf{8}$ & 0 & 0 \\
\hline
\end{tabular}

Fatores (\%): Casca de Abacaxi: - 1 (5 g), 1 (7 g); 0 (6 g); Gordura animal: -1 $(2 \mathrm{~g}), 1(6 \mathrm{~g}) ; 0(4 \mathrm{~g})$.

A produção do biossurfactante foi realizada por fermentação com frascos de $100 \mathrm{~mL}$ do meio, misturando os fatores de acordo com o planejamento experimental. As variáveis casca de abacaxi e gordura animal foram cortadas em pedaços com tamanhos aproximados de $1 \mathrm{~cm}^{2}$ para a uniformização do processo. Os frascos foram mantidos sob agitação orbital por um período de 48 h, 72 h, 96 h e 120 h. Alíquotas foram retiradas até o final da fermentação. As células foram separadas do líquido metabólico por centrifugação a $10.000 \mathrm{~g}$ por $15 \mathrm{~min}$, a $10^{\circ} \mathrm{C}$, com posterior filtração em Millipore de 0,45 $\mu \mathrm{m}$ para separação total das células. $O$ líquido metabólico livre de células foi utilizado para as determinações de tensão superficial e índice de emulsificação.

\subsection{Tensão Superficial}

A tensão superficial do líquido metabólico livre de células contendo o biossurfactante foi medido em um tensiômetro automático (modelo Sigma 70KSV Ltda., Finland), utilizando o anel de DU NUOY, por meio de sua imersão no líquido, registrandose a força requerida para retirá-lo através da interface ar-líquido (KUYUKINA, et al., 2001).

\section{3 İndice de Emulsificação}

A determinação do índice de emulsificação foi realizada durante 24 horas (E24) em todas as condições do planejamento experimental utilizando óleo girassol, óleo pós-fritura e óleo de milho para cada condição produzida. Foi determinado pela adição de $2,0 \mathrm{~mL}$ dos substratos testados em 2,0 $\mathrm{mL}$ do sobrenadante, misturando-se em vórtex por 2 min e deixando em repouso por $24 \mathrm{~h}$. $O$ índice foi calculado como porcentagem da altura da camada emulsificada $(\mathrm{cm})$ dividida pela altura total da coluna do líquido $(\mathrm{cm})$ (COOPER E GOLDENBERG, 1987).

\subsection{Dispersão do óleo de motor queimado}

Seguindo a metodologia descrita por Youssef et al. (2004), o teste foi realizado utilizando uma placa de Petri com $140 \mathrm{~mm}$ de diâmetro com $5 \mathrm{~mL}$ de água mais $15 \mu \mathrm{L}$ do óleo de motor queimado. O volume de $10 \mu \mathrm{L}$ do líquido metabólico livre de células (da melhor condição apresentada - condição 1,48 h) foi adicionado na superfície do óleo e a formação de uma zona clara indicou o tamanho da zona de dispersão, a qual foi medida em $\mathrm{mm}$.

\subsection{Isolamento e Extração do biossurfactante}

O biossurfactante produzido na melhor condição selecionada do planejamento fatorial, com 48 horas de cultivo da S. marcescens UCP 1549 devido à menor tensão superficial, após ter passado por testes de estabilidade frente a pH e força iônica, foi extraído a partir do líquido metabólico livre de células submetido ao processo de extração de acordo com a metodologia descrita por Nitschke e Pastore (2002).

\section{RESULTADOS E DISCUSSÃO \\ 4.1 Tensão superficial}

Após o procedimento de produção do biossurfactante, foi medida a Tensão Superficial das condições produzidas. A Tabela 2 apresenta os resultados das condições fermentadas em modo cinético da bactéria Serratia marcescens UCP 1549 em 48 h, 72 h, 96 h e 120 h. 
Tabela 2 - Resultados da Tensão Superficial (TS) da fermentação em modo cinético da Serratia marcescens UCP 1549 em 48h, 72h, 96h e 120h

\begin{tabular}{|c|c|c|c|c|c|c|}
\hline Condições & Casca de abacaxi & Gordura animal & $\mathrm{T} \mathrm{S}(\mathrm{mN} / \mathrm{m})-48 \mathrm{~h}$ & $\mathrm{~T} \mathrm{~S}(\mathrm{mN} / \mathrm{m})-72 \mathrm{~h}$ & T S (mN/m) - 96h & $\mathrm{T} \mathrm{S}(\mathrm{mN} / \mathrm{m})-120 \mathrm{~h}$ \\
\hline 1 & -1 & -1 & 27,70 & 41,38 & 27,90 & 31,53 \\
\hline 2 & 1 & 1 & 29,46 & 29,46 & 36,50 & 29,52 \\
\hline 3 & -1 & 1 & 34,78 & 36,75 & 36,00 & 30,55 \\
\hline 4 & 1 & -1 & 33,53 & 47,66 & 31,23 & 28,00 \\
\hline 5 & 0 & 0 & 39,01 & 40,13 & 38,50 & 36,98 \\
\hline 6 & 0 & 0 & 40,32 & 40,06 & 37,30 & 30,29 \\
\hline 7 & 0 & 0 & 39,78 & 37,83 & 38,20 & 34,25 \\
\hline 8 & 0 & 0 & 39,65 & 36,40 & 38,40 & 36,30 \\
\hline
\end{tabular}

Fatores (\%): Casca de Abacaxi: -1 (5 g), 1 (7 g); 0 (6 g); Gordura animal: -1 (2 g), 1 (6 g); 0 (4 g).

O melhor resultado apresentado para tensão superficial foi a condição 1 , a qual continha 5 gramas de casca de abacaxi e 2 gramas de gordura animal fermentados por 48 horas com $27,7 \mathrm{mN} / \mathrm{m}$.

Com a finalidade de obter uma análise mais detaIhada da eficiência na redução da tensão superficial por meio da interação das variáveis (casca de abacaxi e gordura animal), foi feito o Diagrama de Pareto realizado pelo pacote computacional "STATISTICA" versão 10, sendo considerada a condição 1, que apresentou melhor resultado de Tensão Superficial. A Fig. 1 apresenta o Diagrama de Pareto para a cinética $155 \mathrm{rpm}$ na produção do biossurfactante em 48, 72, 96 e 120h.
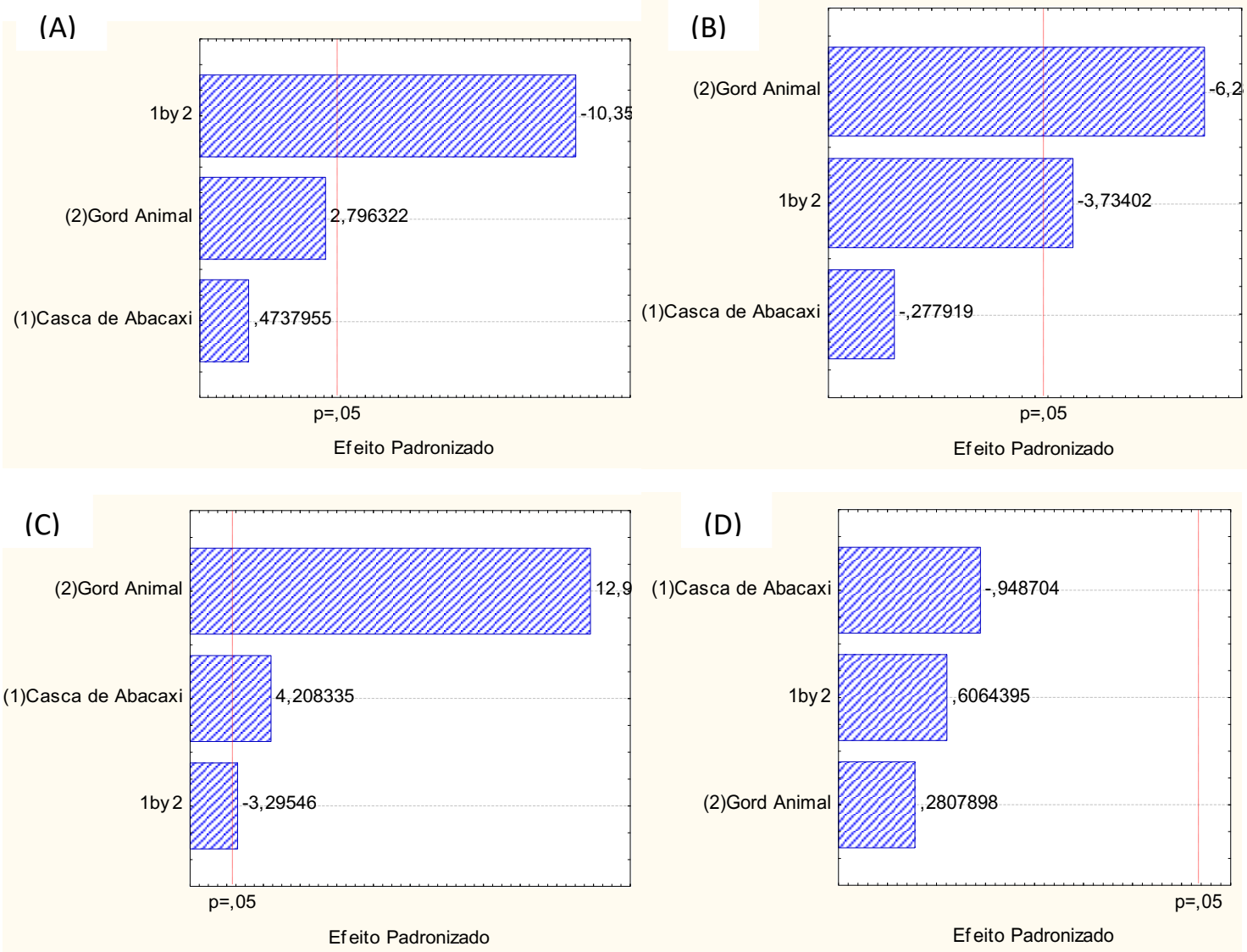

Figura 1 - Diagrama de Pareto para avaliação da Tensão Superficial na produção de biossurfactante utilizando Serratia marcescens UCP 1549 , a $155 \mathrm{rpm}, 28^{\circ} \mathrm{C}$, em 48h (A), 72h (B), 96h (C) e 120h (D) 
De acordo com as Fig. 1 (A) e 1 (B), as interações entre a casca de abacaxi e a gordura animal foram significativas estatisticamente e contribuíram positivamente para a redução da tensão superficial. Entretanto, o efeito da variável independente casca de abacaxi foi estatisticamente representativa, mas contribuiu negativamente para a redução da tensão superficial com as condições estabelecidas pelo planejamento fatorial de $2^{2}$ sobre a variável resposta tensão superficial, após 48 horas de cultivo a $28^{\circ} \mathrm{C}$ e $155 \mathrm{rpm}$ com nível de confiança de $95 \%$.

Na Fig. 1 (C), as interações entre a casca de abacaxi e a gordura animal foram significativas estatisticamente e contribuíram positivamente para a redução da tensão superficial, assim como o efeito das variáveis independentes gordura animal e casca de abacaxi.

Para a Fig. 1 (D), as interações entre a casca de abacaxi e a gordura animal não foram significativas estatisticamente e contribuíram nega- tivamente para a redução da tensão superficial, assim como o efeito das variáveis independentes gordura animal e casca de abacaxi. Portanto, na cinética de $120 \mathrm{~h}$ a redução da tensão superficial não obteve um resultado satisfatório, uma vez que a interação dos substratos analisados não apresentou resultados significativos.

\section{2 İndice de Emulsificação}

O índice de emulsificação avaliado refere-se ao valor quantitativo da emulsão produzida pelo biossurfactante presente no líquido metabólico, e quanto maior esse valor, mais estável será a emulsão formada. As análises de índice de emulsificação, de acordo com o planejamento estatístico, foram representadas a partir de gráficos comparativos entre os diferentes tipos de óleo (pós-fritura, girassol e milho) e tempos de rotação. A Fig. 2 mostra o comparativo dos Índices de Emulsificação para as condições do modo cinético de $48 \mathrm{~h}$, $72 \mathrm{~h}, 96 \mathrm{~h}$ e $120 \mathrm{~h}$ a $28^{\circ} \mathrm{C}$, modo cinético.

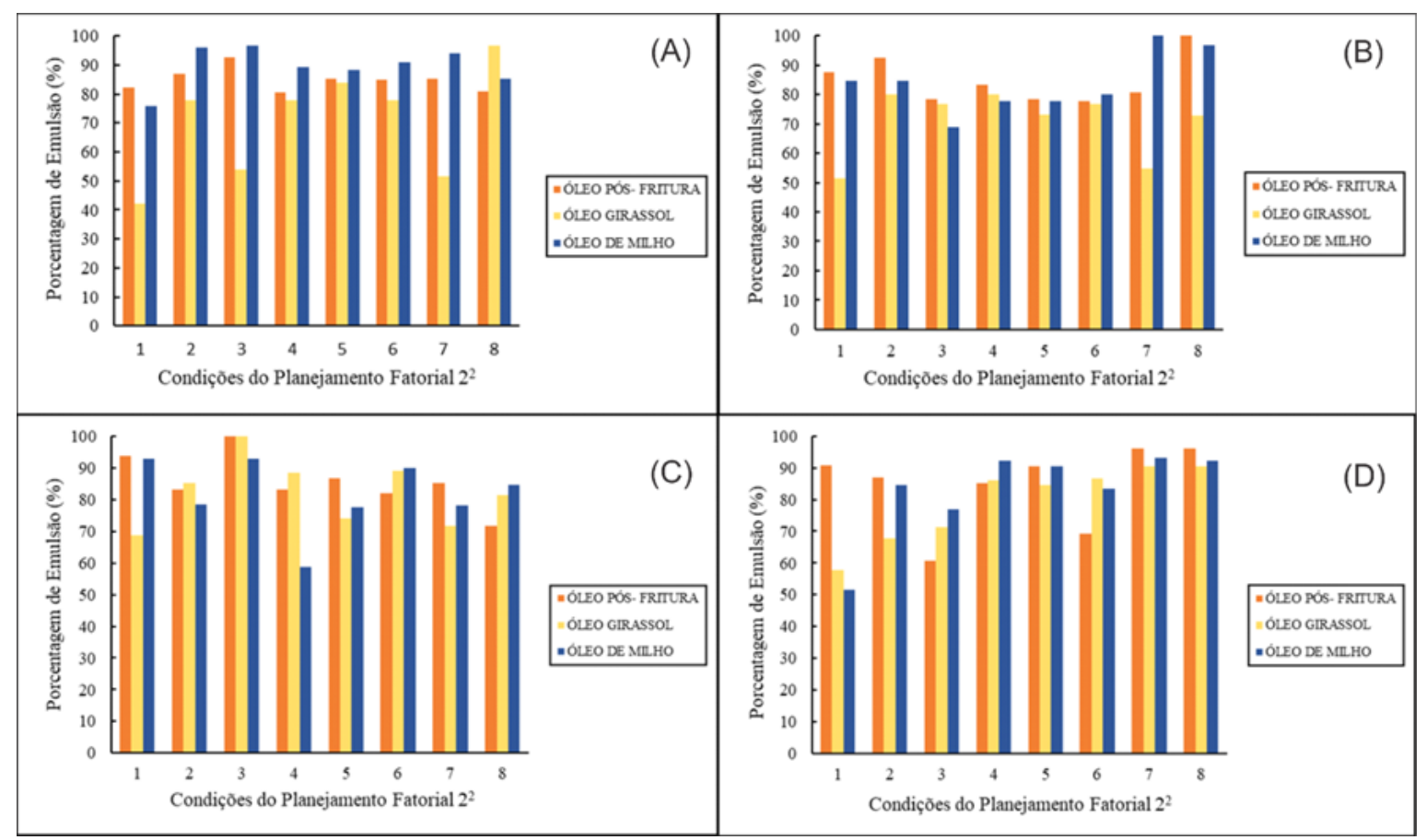

Figura 2 - Comparativo dos Índice de Emulsificação em 48h (A), em 72h (B), em 96h (C), em 120h (D) 
A capacidade de emulsificação foi mais bem observada na condição 3 apresentada na Fig. 2 (C), que continha 5 gramas de casca de abacaxi e 6 gramas de gordura animal, fermentada por 96 horas utilizando o óleo pós-fritura e óleo girassol, com uma emulsão de $100 \%$. Concomitantemente, obteve-se o mesmo resultado para as condições 7 e 8 da Fig. 2 (B), fermentadas por 72 horas, utilizando o óleo de milho e óleo pós- fritura, respectivamente.

\subsection{Teste de dispersão}

A capacidade de dispersão ou agregação de manchas de petróleo foi simulada no laboratório, contaminando-se amostras de água com óleo de motor queimado. Para esse teste foi utilizada a melhor condição selecionada do planejamento experimental, ou seja, condição que contém 5 gramas de casca de abacaxi e 2 gramas de gordura animal fermentados por 48 horas, devido à menor tensão superficial. 0 resultado foi observado visualmente como apresentado na Fig. 3, mostrando uma zona clara espessa com 100,8 mm de dispersão.

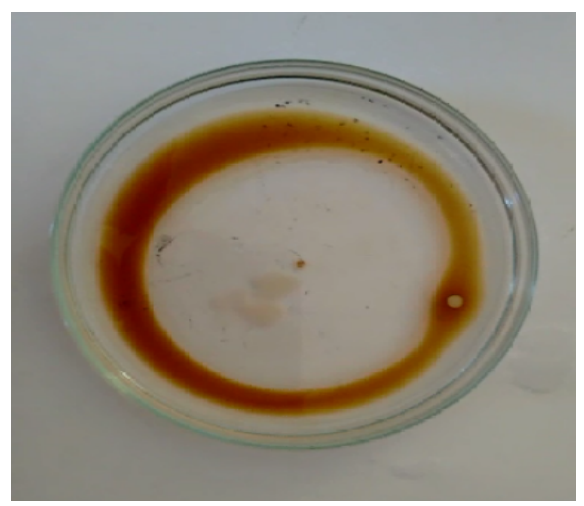

Figura 3 - Teste de dispersão do Biossurfactante com óleo de motor queimado

\subsection{Extração do Biossurfactante}

O biossurfactante produzido na melhor condição selecionada do planejamento experimental, ou seja, condição que contém 5 gramas de casca de abacaxi e 2 gramas de gordura animal fermentados por 48 horas, devido à menor tensão superficial, foi extraído de $1 \mathrm{~L}$ do líquido metabólico livre de células, seguido de filtração em membrana de millipore e acidificado com uma solução de $\mathrm{HCl}$ $5 \mathrm{~N}$ até atingir $\mathrm{pH} 2,0$.

Colocou-se então para descansar por $16 \mathrm{~h}$ e centrifugou-se o sistema, descartando o sobrenadante e recolhendo o precipitado para ficar na estufa por aproximadamente $24 \mathrm{~h}$, a uma temperatura de $37^{\circ} \mathrm{C}$. A Fig. 4 representa o resultado desse isolamento e extração.

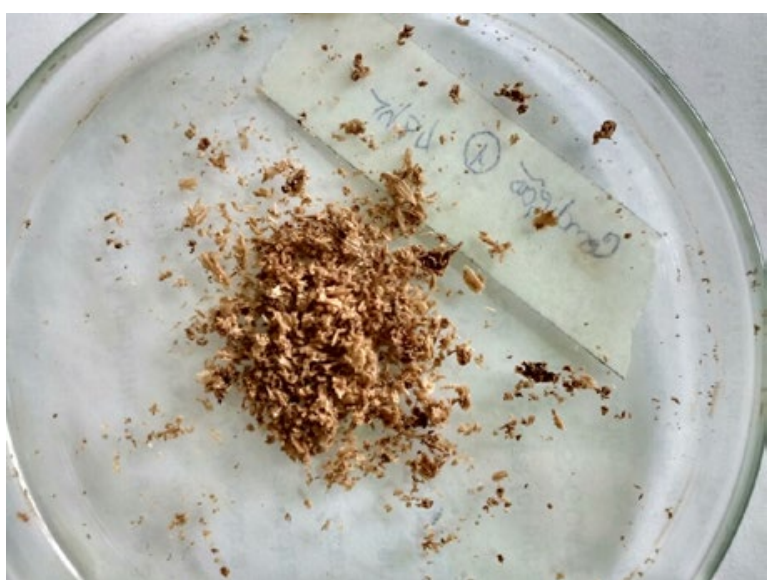

Fig. 4 - Pó extraído do Biossurfactante utilizando Serratia marcescens UCP 1549

\section{DISCUSSÃO}

\subsection{Análise da variável Tensão Superficial}

Entre as condições analisadas, a que apresentou o melhor resultado para tensão superficial, de acordo com os dados apresentados na Tabela 2, foi a condição 1 que continha 5 gramas de casca de abacaxi e 2 gramas de gordura animal fermentados por 48 horas com 27,7 mN/m. Esse resultado exibiu uma grande atividade superficial, propriedade esta que o caracteriza como um bom tensoativo. 
Alves et al. (2014) utilizando a Serratia marcescens UCP 1549 com o mesmo meio de cultivo das condições analisadas, obteve o melhor resultado de tensão superficial com o valor de 33,0 mN/m.

De acordo com o Diagrama de Pareto feito para as condições obtidas, as interações entre a casca de abacaxi e a gordura animal foram significativas estatisticamente e contribuíram positivamente para a redução da tensão superficial. Os resultados mais satisfatórios foram para as condições com rotação de 155 rpm em 96 horas, uma vez que tanto o efeito das variáveis independentes gordura animal e casca de abacaxi como a interação entre elas foram significativas estatisticamente e contribuíram positivamente para a redução da tensão superficial.

De acordo com Nistchke e Pastore (2002), os biossurfactantes são mais eficientes e efetivos com relação à atividade superficial e interfacial do que os surfactantes convencionais (detergentes aniônicos sulfatados), pois produzem menor tensão superficial com menores concentrações de produto ativo. Como exemplo, o dodecilsulfato de sódio (SDS) usualmente apresenta concentração micelar crítica em torno de 20232890 mg/L e redução da tensão superficial de 72 $\mathrm{mN} / \mathrm{m}$ para $37 \mathrm{mN} / \mathrm{m}$, enquanto alguns biossurfactantes apresentam valores de tensão superficial em torno de $26-29 \mathrm{mN} / \mathrm{m}$ e de concentração micelar crítica 50-200 mg/L, como corroborado também pelos resultados obtidos neste trabalho.

\subsection{Análise da variável Îndice de Emulsificação}

A capacidade de emulsificação foi mais bem observada na condição 3 apresentada na Fig. 2 (C), que continha 5 gramas de casca de abacaxi e $6 \mathrm{~g}$ de gordura animal, fermentados por 96 horas utilizando o óleo pós-fritura e óleo girassol, com uma emulsão de $100 \%$. Na análise dos resultados de todas as condições referentes à emulsificação do óleo de girassol neste trabalho, observou-se que a efetividade dos biossurfactantes foi baixa quando comparada com a efetividade de emulsão formada pelos óleos pós-fritura e milho.

Martins (2017) obteve uma produção eficiente de biossurfactante utilizando o microrganismo Corynebacterium aquaticum e peixe e resíduos de bagaço como fonte de carbono. A tensão superficial obtida para esses tratamentos foi de 27,8 e $33,9 \mathrm{mN} / \mathrm{m}$ e a capacidade de emulsão foi de 87,6 e $61,6 \%$, respectivamente.

Desta forma, é possível observar que o biossurfactante produzido com o microrganismo Serratia marcescens teve um resultado satisfatório quanto aos resultados apresentados de índice de emulsificação. Lopes (2014) constatou que o biossurfactante produzido na sua pesquisa apresentou maiores valores de emulsificação para o hidrocarboneto estudado, o óleo lubrificante automotivo, em relação ao detergente químico.

\subsection{Análise do teste de dispersão}

A formação da zona clara na Fig. 3 indicou o tamanho da zona de dispersão, a qual foi medida por uma régua com um resultado de $100,8 \mathrm{~mm}$, apresentando assim uma dispersão do óleo de motor queimado de $72 \%$ na água. Portanto, pôde-se observar que o experimento apresentou uma excelente dispersão e uma boa estabilidade durante o processo.

Carvalho (2012) estudou 66 isolados bacterianos quanto à produção de biossurfactantes e, para tanto, utilizou a metodologia da dispersão do óleo, utilizando $100 \mu \mathrm{l}$ de óleo diesel, para identificar as bactérias mais promissoras. Como resultado, encontrou que todas as linhagens apresentaram a produção de algum halo de dispersão, mas apenas 17 (equivalente a 25\%) foram capazes de gerar halos com o diâmetro total da placa de Petri, indicando assim a produção do biossurfactante. Portanto, ele também obteve 
um resultado satisfatório utilizando microrganismos diferentes.

\subsection{Extração do Biossurfactante}

O pó extraído, representado na Fig. 4, apresentou $+0,8677 \mathrm{~g} / \mathrm{L}$, representando a quantidade de biossurfactante desidratado obtido em $1 \mathrm{~L}$ do líquido metabólico. Segundo o trabalho de Alves et al. (2017), durante o cultivo submerso do microrganismo P. sajor-caju obteve-se 0,70 \pm 0,03 $\mathrm{g} / \mathrm{L}$ de biossurfactante desidratado para o experimento utilizando óleo de soja comercial e 0,63 $\pm 0,04 \mathrm{~g} / \mathrm{L}$ para o experimento utilizando óleo de soja residual de fritura.

\section{CONCLUSÕES}

Os biossurfactantes podem ser sintetizados utilizando procedimentos e substratos relativamente simples e com menor custo a partir de substratos renováveis. Pode-se concluir então que a eficiência do biopolímero produzido por S. marcescens UCP 1549 foi de boa qualidade, uma vez que, utilizando resíduos agroindustriais como casca de abacaxi e gordura animal, os quais são considerados rejeitos pela maioria das indústrias, obtiveram-se resultados satisfatórios para a produção do biossurfactante. O biossurfactante produzido na melhor condição selecionada do planejamento experimental (condição com 5 gramas de casca de abacaxi e 2 gramas de gordura animal fermentados por 48 horas), devido à menor tensão superficial, apresentou um resultado de $27,7 \mathrm{mN} / \mathrm{m}$. Este mostrou um ótimo potencial de metabolização dos rejeitos industriais como fonte de Carbono e Nitrogênio para seu crescimento, gerando assim, insumos com alto valor biotecnológico.

Portanto, pode-se comprovar a capacidade de emulsificação do biossurfactante produzido pela bactéria Serratia marcescens UCP 1549, uma vez que esse foi capaz de formar emulsões entre duas fases fluidas que apresentavam diferentes graus de polaridade, chegando a apresentar $100 \%$ de emulsão. 0 biossurfactante produzido tem potencial de aplicação na descontaminação ambiental de petróleo e derivados com um baixo custo, uma vez que um fator responsável pela diminuição desse custo seria a necessidade de concentrações inferiores de biossurfactante em relação ao surfactante químico para atingir os resultados esperados.

Ainda como vantagem em potencial desses produtos estaria a substituição ou redução da quantidade utilizada de produtos sintéticos não biodegradáveis ou pouco biodegradáveis por produtos de origem natural, obtidos por meio do cultivo de microrganismos em substratos renováveis. As indústrias teriam redução de custos com o tratamento dos resíduos, que seriam mais facilmente degradados devido à ausência/ redução de produtos pouco biodegradáveis no efluente final, os quais dificultam o tratamento.

\section{CONTRIBUIÇÃO DOS AUTORES}

Todos os autores contribuíram de forma igualitária.

\section{REFERÊNCIAS}

ALVES, E. P., TAVARES. L. B. B., GERN, R. M. M., SILVA, D. A. K., FURLAN, S. A., WISBECK, E. Produção e caracterização de biossurfactantes metabolizados por Pleurotus sajor-caju a partir de óleo de soja, Revista Matéria, v. 22, n. 03, 2017.

ALVES, T. S.; SALGADO, J. P.; ANDRADE, R. F. S.; MONTERO-RODRÍGUEZ, D.; W. FERREIRA, B.; ALMEIDA, M. M.; TAKAKI, G. M.; ARAÚJO, H. W. C. Production and Evaluation of Biosurfactant by Serratia marcescens UCP 1549 Using Industrial Wastes. Br. Biotechnol. J., v. 4, n. 6, p. 708-719, 2014. http://doi.org/10.9734/ BBJ/2014/9774

BARROS, F. F. C., QUADROS, C. P. D., MARÓSTICA JÚNIOR, M. R., PASTORE, G. M. Surfactina: propriedades químicas, tecnológicas e funcionais para aplicações em alimentos. Química Nova, 2007. http://doi.org/10.1590/S0100-40422007000200031 
BERGER, L.R.R.; STAMFORD, T.C.M.; STAMFORD-ARNAUD, T.M.; DE OLIVEIRA FRANCO, L.; DO NASCIMENTO, A.E.; CAVALCANTE, H.M.M.; MACEDO, R.O.; DE CAMPOS-TAKAKI, G.M. Effect of Corn Steep Liquor (CSL) and Cassava Wastewater (CW) on Chitin and Chitosan Production by Cunninghamella elegans and Their Physicochemical Characteristics and Cytotoxicity. Molecules. 19, 2771-2792, 2014. http://doi.org/10.3390/molecules19032771

CAMPOS-TAKAKI, G.M.; SARUBBO L.A, ALBUQUUERQUE C.D. Environmentally friendly biosurfactants produced by yeasts. Adv Exp Med Biol. 672, 250-60, 2010. http://doi.org/10.1007/978-14419-5979-9_19

CARVALHO, L. C. T. Produção de Lipases e biossurfactantes por bactérias isoladas de um solo contaminado com óleo vegetal, 2012. Dissertação (Mestradoem Ciências Exatas e da Natureza), Universidade Federal da Paraíba, João Pessoa.

COOPER, D. G. and GOLDENBERG, B. G. Surface active agents from two Bacillus species, Appl. Environ. Microbiol., v. 53, p 224 -229, 1987. http://doi.org/0099-2240/87/020224-06\$02.00/0

IBRAHIM, M.L., IJAH, U.J.J., MANGA, S.B., BILBIS, L.S., UMAR, S. Production and partial characterization of biosurfactant produced by crude oil degrading bacteria. Int. Biodeterior. Biodegrad. 81, 28-34, 2013. http://doi.org/10.1016/j.ibiod.2012.11.012

KUYUKINA, M.S, IVSHINA I.B., PHILPJ.C, CHRISTOFI N, DUNBARS.A, RITCHKOVA, M.I. Recovery of Rhodococcus biosurfactants using methyl tertiary-butyl rther extrction. J Microbiol Met 46: 109120.2001. http://doi.org/10.1016/S0167-7012(01)00259-7

LAWNICZAK, L., MARECIK, R., CHRZANOWSK, L. Contributions of biosurfactants to natural or induced bioremediation. Appl. Microbiol. Biotechnol. 97, 2327-2339, 2013. https://doi.org/10.1007/ s00253-011-3589-4

LI, J., DENG, M., WANG, Y., CHEN, W. Production and characteristics of biosurfactant produced by Bacillus pseudomycoides BS6 utilizing soybean oil waste. Int. Biodeterior. Biodegrad. 112, 72-79, 2016. https://doi.org/10.1016/j.ibiod.2016.05.002

LOPES, P. R. M. Biorremediação de solo contaminado com óleo lubrificante pela aplicação de diferentes soluções de surfac- tante químico e biossurfactante produzido por Pseudomonas aeruginosa LBI. Tese (Doutorado), Instituto de Biociências do Campus de Rio Claro, Universidade Estadual Paulista, 2014.

MANEERAT, S. Production of biosurfactants using substrates from renewable resources. Songklanakarin J. Sci. Technol., 2005.

MARTINS, P. C., MARTINS, V. G. Biosurfactant production from industrial wastes with potential remove of insoluble paint, International Biodeterioration \& Biodegradation n.127, p.10-16, 2017. https://doi.org/10.1016/j.ibiod.2017.11.005

MORAIS, K.A.D., SOARES, R.S., ARAÚJO, M.V.F., OLIVEIRA, B.F.R., VIEIRA, J.D.G. Produção de biossurfactante por Bacillussp. em meio mínimo contendo glucose. Enciclopédia Biosfera, 11(22):38843894, 2015.

NISTCHKE, M.; PASTORE, G.M. Biossurfactantes: Propriedades e Aplicações. Revista Química Nova, Campinas, vol.25, n.5, p. 772 - 776, 2002. https://doi.org/10.1590/S010040422002000500013

OKORO, C.; AGRAWAL, A; CALLBECK, C. Simultaneous biosurfactant production and hydrocarbon biodegradation by the resident aerobic bacterial flora of oil production skimmer pit at elevated temperature and saline conditions. Life Science Journal, v. 9, n. 3 , p. 356-364, 2012. ISSN: 1097-8135

OLKOWSKA, E.; RUMAN, M.; POLKOWSKA, Z. Occurrence of Surface Active Agents in the Environment. Journal of Analytical Methods in Chemistry. v. 2014, 2014. https://doi. org/10.1155/2014/769708

REDDY, V.; TORATI, R. S.; OH, S.; KIM, C. Biosynthesis of gold nanoparticles assisted by Sapindus mukorossi Gaertn. Fruit pericarp and their catalytic application for the reduction of p-nitroaniline. Industrial \& Engineering Chemistry Research, v. 52, n. 2, p. 556564, 2012. https://doi.org/10.1021/ie302037c

YOUSSEF, N.H.; DUNCAN, K.E.; NAGLE, D.P.; SAVAGE, K.N.; KNAPP, R.M; MCINERNEY, M.J. Comparison of methods to detect biosurfactant production by diverse microrganisms. Journal of Microbiological Methods, v. 56, p. 339-347, 2004. https://doi.org/10.1016/j.mimet.2003.11.001 